\title{
The Impact of Air Pollution on the Development of Inbound Tourism in Chinese Megacities: The Case Study of Beijing, Guangzhou and Chongqing
}

\author{
Nianlin ZHOU ${ }^{1}$, Yeli GU and Manyuan JIANG \\ South China Business College, Guangdong University of Foreign Studies, 181 \\ Liangtian M. Rd., Baiyun District, 510545 Guangzhou, China
}

\begin{abstract}
The existing studies pay more attention to the impact of public transport and other public service facilities on urban air pollution and tourism, but less on the negative effect of air pollution caused by carbon emissions of business fixed investment on inbound tourism. This article attempts to make a supplementary analysis about the above point through examining the correlation between air pollution associate with business fixed investment and the size of inbound tourism based on panel data of three megacities (Beijing, Guangzhou and Chongqing) in China over the period from 2015 to 2019. The findings of this paper show that the effects of air pollution linked with carbon emissions from business fixed investment on the number of inbound tourists (NIT) is a negative correlation, while the influence of GDP per capita and tourism revenue on NIT reveal a positive relationship by applying fixed effects model for benchmark regression and the system-GMM estimator for robustness check. Moreover, the negative influence of PM 10 on sample cities is more than PM2.5. Some different results of core variables between benchmark and sub-sample regressions don't imply the above conclusion to be substantively changed because of different distribution and concentration of nominal inbound tourists in specific sample megacities. In order to fundamentally improve air quality and to stimulate the development of inbound tourism, the suggestion of this study is to promote new business fixed investment with clean energy of renewable and low carbon.
\end{abstract}

Keywords: Air pollution, impact, inbound tourism, megacities

\section{Introduction}

In current global transition period in which pursues sustainable development, it has become a global agenda for countries to stimulate low-carbon economic growth and eco-tourism through promoting clean energy. Finnish government, for example, is developing new technologies and smart practices through offering diverse subsidies, incentives and distributing biogas and electric fuels for businesses and citizens, so that push forward disusing fossil fuels. Denmark generated half of its electricity from solar and wind power in 2019 and is trying to realize $100 \%$ renewable energy in the future [1]. Sweden is promoting the target of zero emissions of greenhouse gases by 2045 by

${ }^{1}$ Corresponding author: Nianlin Zhou, South China Business College, Guangdong University of Foreign Studies, 181 Liangtian M. Rd., Baiyun District, 510545 Guangzhou, China; E-mail: gwjdyjzx@163.com. 
introducing a climate policy framework as per the climate goals with a set of orderly and stable emission reduction actions [2]. Chinese government announced to reduce $60 \%-65 \%$ of carbon intensity by 2030 and to drive carbon emission to zero by 2060 [3]. The aims of decreasing carbon emission of different countries are engendering a profound influence on the model of economic growth and the development of tourism.

Megacities are the centers of enhancing business fixed investment for economic growth and expanding inbound tourism development in China. On the one hand, the improvement of tourism infrastructure and service facilities need to rely on business fixed investment. On the other hand, air pollution linked with high emissions by way of investment on fixed asset leads to a negative impact on the size of inbound tourism. How to lower air pollution to enlarge inbound tourism and to keep sustainable economic growth would be the focus of research.

This article examined the correlation between the size of inbound tourists and air pollution associated with carbon emission from business fixed investment based on the empirical analysis of Chinese megacities, Beijing, Guangzhou and Chongqing. The purpose is to suggest that one of fundamental ways to cut down air pollution and to expand the size of inbound tourist must proceed from promoting technological innovation of new energy and new infrastructure investment.

The possible contribution of this study is to introduce investment on fixed asset linked with carbon emissions into the research that focuses on improving air pollution and promoting inbound tourism development. The existing studies pay more attention to the impact of public transport and other public service facilities on urban air pollution, but less on the negative effect of air pollution caused by carbon emissions of business fixed investment on inbound tourism. This paper attempts to make a supplementary analysis.

\section{Literature review}

As the inbound tourism centers, megacities have been widely studied about their functions of providing services for tourists, environment condition of developing tourism, and the influence of air quality on tourists.

Some scholars stress the functions and contribution of urban tourism. Wan et al. [4] point out that tourist megacities have comprehensive functions to improve capacities of tourism infrastructure, services, destination management and ecological environment condition through policy coordination on the one hand, and to provide multifunction services in tourist destinations, culture entertainment, restaurants, public facilities for tourists on the other [5-6]. The boom of urban tourism has also made contribution to increase employment, consumption and local economic growth [7]. Others describe a whole picture about the elements affecting urban tourism, in which include rank and abundance in tourism resources, service facilities for tourists, tourism infrastructure, the quality of tourist products and information about tourism destination influenced on tourist's decisions or choices [5].

Most of all, studies have paid common attention to the significance of environmental and air state that may influence on tourist choice and urban tourism development [5,8-9]. Since the development of tourism heavily depends on high-quality ecological environment and natural resources [10], air quality has been one of the important indicators to measure whether a city reaches the standard of international tourism city [11]. Moreover, arguments discuss different types caused 
environmental pressure in tourist cities. Tourist traffic, for example, with increasing travel of tourists from one city to other, has led to high exhaust emissions and environmental problems via energy consumption of public transportation [12-15]. In particular, the main categories of air pollution, including dusts (PM2.5 and PM10), tropospheric ozone, sulfur oxides (SO) and nitrogen oxides, which definitely impact on urban tourism, are described in academic circles [16-18]. The monthly average concentrations of $\mathrm{SO}_{2}, \mathrm{PM} 2.5$ and PM10 have a more significant negative externality on the scale of inbound tourism in megacities than in non-central cities [19]. Moreover, the concern of potential overseas tourists about air quality and haze goes beyond the attraction of core attractions, such as history, culture and nature, and becomes the main factors hindering their intention to come over to China [20]. The risk perception of tourists, that is, fear and anxiety about the potential risks of a tourist destination, would drive them to give up visiting a certain place [21]. Saenz concludes that the increase and decrease of tourists' daily stock is an important indicator to evaluate the level of air pollution in urban [22].

In terms of sources of air pollution, literatures have studied the impact of public transportation on inbound tourism, but a few have analyzed the influence of business fixed investment on tourism. One more important function of Chinese megacities is to promote inbound tourism and economic growth by increasing investment on fixed assets. In other words, the issue of air pollution in megacities mirrors a common situation of relying on fossil fuels for business fixed investment heavily at the present stage for stimulating both economic growth and inbound tourism in China [23]. A number of empirical analysis indicate that the aggravation of air pollution is associated with increasing investment on fixed assets (IFA), power consumption and vehicle exhaust emission due to industrialization and urbanization of scale expansion in China [24-26]. Particularly, among six kinds of greenhouse gases in industrial carbon emissions, there are five of which are related to PM2.5 [27].

Hence, the impact from both air pollution and business fixed investment with carbon emission on the size of inbound tourists would be taken into account in this study.

\section{Methods}

\subsection{Data and Variables}

\subsubsection{Data Sources}

This paper uses a sample consisting of a panel data with 180 observations in three major tourist cities, Beijing, Guangzhou and Chongqing, in China over the period from 2015 to 2019 on monthly based. The data of the numbers of inbound tourist (NIT) are obtained from the published official database of bureaus of culture, radio, television and tourism in Beijing, Guangzhou and Chongqing separately. We collected the air monthly data of urban in which include the air pollution of particulate matter (PM2.5), inhalable particulate matter (PM10) and sulfur dioxide (SD) in the sample cities according to the published data from environmental monitoring of China. The data of GDP per capita (AGDP), investment on fixed assets (IFA), tourism revenue (TR) and consumer price index (CPI) are gotten from bureaus of statistics of these cities, and foreign exchange rate between RMB and US dollar (FER) from state administration of foreign exchange of China. We used STATA15 program for the empirical analysis. 


\subsubsection{Variables}

Dependent Variable: The Number of Inbound Tourists (NIT). We take the number of inbound tourists as the dependent variable because it is a widely accepted indicator to explain the scale of inbound tourism [28] and the extent of sustainable development of tourism in international tourist cities [29].

Independent variable: total air pollution (TAP). It includes particulate matter 2.5(PM2.5), inhalable particulate matter 10 (PM10) and sulfur dioxide (SD). Air pollution is recognized as the main downturn cause of inbound tourism in China [30]. The monthly data of air pollution from 2015 to 2019 are selected as the core explanatory variables for the sample cities.

Control variables: GDP per capita (AGDP), investment on fixed assets (IFA), tourism revenue (TR), consumer price index (CPI) and foreign exchange rate (FER). We introduce a number of control variables that are known by both Chinese and foreign literature for influencing on tourism development and the number of inbound tourists in megacities. For instance, GDP per capita is used as a characterization index of economic development level, which is obtained by GDP dividing by resident population of sample megacities. In addition, investment on fixed assets (IFA) is an important control variable. Because there are four major industrial sectors, that is, energy, industry, transportation and real estate sectors, account for $81 \%$ of total carbon emission in China [31], three of which (except energy) have been heavily invested in megacities by business fixed investment in infrastructure and real estate which extensively use diesel vehicles with serious exhaust emissions. Thus, investment on fixed assets should be one of key sources linked with carbon emission and directly affects on air quality in the above cities. As tourism is recognized as a momentous source of income for megacities [5] and assesses the operation efficiency of tourism sector, this research takes tourism revenue as the proxy variable of tourism resource endowment [28] and the total number of star hotels [32]. The possible effects of foreign exchange rate between US dollar and RMB and CPI on spending of inbound tourists are considered as well.

In order to eliminate heteroscedasticity, those variables are measured by the natural logarithm. Table 1 provides the definition of variables.

Table 2 indicates the descriptive statistics for main variables. The average TAP in the sample is 4.785 with a standard deviation of 0 . 35. The value gap between the maximum (5.799) and the minimum (3.931) is not wind. It implies that the air quality has not been significantly improved. Meanwhile, two of key air pollution sources, PM10 and PM2.5, have the mean value of 4.195 and 3.763 with the standard deviation of 0.34 and 0.41 , respectively.

\section{Model, Results and Robustness Test}

\subsection{Model}

This study employs the following equation to test the correlation between NIT and TAP after controlling the five factors that may affect NIT in given cities by applying the fixed effects (FE) regression model. 
The characteristic of the fixed effect model is reflected by adding n- 1 dummy variables into the linear regression model, so that each section has a constant term. The changes of panel data are associated with individuals rather than with time in the regression of fixed effect [33]. Furthermore, this model just compares the selected groups of variables, and the conclusion is only applicable for the specific categories of each independent variable to be considered in the study [34]. This research aims to assess the influence of air pollution on the size of inbound tourism, and the different component of inbound tourists between real tourists ${ }^{2}$ and nominal travellers and their distribution in the sample megacities are not the random samples. Therefore, we use the fixed effect model of urban panel data for sample self-selection and empirical analysis.

Table 1. Definition of variables.

\begin{tabular}{|c|c|}
\hline Variables & Definitions \\
\hline $\begin{array}{l}\text { Dependent variables } \\
\text { The numbers of inbound tourist (NIT) }\end{array}$ & $\begin{array}{l}\text { Logarithm of the numbers of inbound tourist in } \\
\text { three major tourist cities in China }\end{array}$ \\
\hline $\begin{array}{l}\text { Independent variables } \\
\text { Total air pollution }(T A P)\end{array}$ & $\begin{array}{l}\text { Logarithm of total air pollution including } \\
\text { PM } 2.5, \text { PM10 and Sulfur dioxide of the sample } \\
\text { cities }\end{array}$ \\
\hline Particulate matter 2.5(PM2.5) & $\begin{array}{l}\text { Logarithm of particulate matter } 2.5 \text { of the } \\
\text { sample cities }\end{array}$ \\
\hline Inhalable particulate matter $10(P M 10)$ & $\begin{array}{l}\text { Logarithm of inhalable particulate matter } 10 \text { of } \\
\text { the sample cities }\end{array}$ \\
\hline Sulfur dioxide $(S D)$ & $\begin{array}{l}\text { Logarithm of sulfur dioxide of the sample } \\
\text { cities }\end{array}$ \\
\hline $\begin{array}{l}\text { Control variables } \\
\text { GDP per capita }(A G D P)\end{array}$ & 然 \\
\hline Tourism revenue $(T R)$ & $\begin{array}{l}\text { Logarithm of tourism revenue referring to the } \\
\text { income sum of tourists' consumption in } \\
\text { different tourist areas obtained by tourism } \\
\text { sector }\end{array}$ \\
\hline Investment on fixed assets (IFA) & $\begin{array}{l}\text { Logarithm of investment on fixed assets } \\
\text { including investment on infrastructure, real estate } \\
\text { sector and renovation }\end{array}$ \\
\hline Consumer price index $(C P I)$ & $\begin{array}{l}\text { Logarithm of CPI on the basis of the last year's } \\
\text { index }\end{array}$ \\
\hline Foreign exchange rate (FER) & $\begin{array}{l}\text { Logarithm of foreign exchange rate between } \\
\text { RMB and US dollar }\end{array}$ \\
\hline
\end{tabular}

Table 2. Descriptive statistics of main variables.

\begin{tabular}{lrccc}
\hline Variable & Mean & Std. Dev. & Minimum & Maximum \\
\hline Ln(NIT)(ten thousand people) & 3.713 & 0.531 & 1.964 & 4.657 \\
$\operatorname{Ln}(T A P)$ (Density) & 4.785 & 0.349 & 3.931 & 5.799 \\
$\operatorname{Ln}(P M 2.5)$ (Density) & 3.763 & 0.413 & 2.772 & 5.023 \\
$\operatorname{Ln}(P M 10)$ (Density) & 4.195 & 0.337 & 3.401 & 5.170 \\
Ln(SD) (Density) & 2.200 & 0.511 & 0.693 & 7.202 \\
$\operatorname{Ln}(A G D P)$ (RMB billions) & 11.079 & 0.757 & 9.302 & 12.427 \\
$\operatorname{Ln}(I F A)$ (RMB ten billions) & 17.427 & 0.956 & 15.198 & 19.048 \\
$\operatorname{Ln}(T R)$ (RMB billions) & 13.020 & 1.782 & 9.144 & 16.297 \\
$\operatorname{Ln}(C P I)$ & 4.621 & 0.011 & 4.599 & 4.644 \\
$\operatorname{Ln}(F E R)$ & 6.496 & 0.042 & 6.415 & 6.563 \\
\hline
\end{tabular}

$$
\begin{aligned}
\operatorname{Ln}\left(N I T_{i, t}\right)= & \alpha_{0}+\beta_{1} \operatorname{Ln}\left(T A P_{i, t}\right)+\beta_{2} \operatorname{Ln}\left(A G D P_{i, t}\right)+\beta_{3} \operatorname{Ln}\left(I F A_{i, t}\right)+\beta_{4} \operatorname{Ln}\left(T R_{i, t}\right) \\
& +\beta_{5} \operatorname{Ln}\left(C P I_{i, t}\right)+\beta_{6} \operatorname{Ln}\left(F E R_{i, t}\right)+\varepsilon_{i, t}
\end{aligned}
$$

${ }^{2}$ Tourists just for going sightseeing are identified as real tourists in this paper. Nominal tourists involve foreign visitors for the purpose of international business, transnational conference, service staffs and employees (BCSEs) which are recognized as "tourists" by Chinese bureaus of statistics. Source: National Bureau of Statistics, China. https://data.stats.gov.cn/easyquery.htm?cn=C01. 
Where subscript $i$ and $t$ represent city and time separately; NITit represents the number of inbound tourists for city $i$ th at time $t$; TAPit symbolizes the total air pollution in city $i$ th at time $t$, in which contains particulate matter 2.5 (PM2.5), inhalable particulate matter 10 (PM10), and sulfur dioxide (SD), respectively. All of variables, including control variables from $\beta_{2}$ to $\beta_{6}$ in the equation, are measured by the natural logarithm.

\subsection{Results}

Table 3 presents the regression results of the correlation between dependent and independent variables. There is a significant negative correlation between the total air pollution (TAP)and the numbers of inbound tourist (NIT) (coefficient $=-0.246 ; p<$ $0.001)$. It means that a $1 \%$ increase in TAP may lead to reduce $0.246 \%$ of NIT. In models (2), (3) and (4), PM2.5, PM10 and SD, each of them has a statistically and significantly negative association with NIT (coefficient $=-0.240 ; \mathrm{p}<$ 0.001),.(coefficient $=-0.251 ; \mathrm{p}<0.001$ ) and (coefficient $=-0.110 ; \mathrm{p}<0.05$ ). These results show that poor air quality, regardless what kind of source for air pollution, generally has a negative relationship with NIT. Therefore, the number of inbound tourists drops when the level of air pollution increases.

With regard to control variables that are considered in this study, the regression results report that the effects of GDP per capita (AGDP) and tourism revenue (TR) on NIT are positive and highly significant. The positive relationship could be the result of inbound tourist consumption as a part of GDP per capita and tourism revenue. However, the significant negative correlation of the investment on fixed assets (IFA) with NIT suggests that carbon emission during the investment processes plays a negative role in the inbound scale of foreign tourists. Two more control variables, FER and CPI, don't present statistical significant results with NIT.

The aforementioned findings confirm a negative relationship between air pollution and the number of inbound tourists during the sample period of 2015-2019, which is statistically significant at the level of $1 \%$. More importantly, two sources of air pollution, PM10 and PM2.5, show serious impact on inbound tourists. As Table 3 displays that a $1 \%$ increase in PM10 or PM2.5 leads to reduce the number of inbound tourists (NIT) by $0.251 \%$ and $0.240 \%$, correspondingly. The negative influence of PM 10 on sample cities is even more than PM2.5. Furthermore, IFA presents negative relationship with NIT. When investment on fixed assets increases by $1 \%$, the number of tourists reduces by $0.168 \%$. As carbon emission, including PM2.5, PM10 and SD, constitutes the main source of air pollution in the processes of IFA. Thus, as expected, the number of inbound tourists may continue to decline if carbon emission of IFA is not substantially improved. Simply, the higher the level of air pollution is, the less the number of tourists will be. On the other hand, the effects of AGDP and TR on NIT are positive and highly significant. It means that inbound tourism has a significant contribution to push up GDP per capita and tourism revenue as well.

Also, the VIF (variance inflation factor) in all of variables is less than two which illustrates that multicollinearity is very low. 
Table 3. Regression results for the correlation between air pollution and inbound tourism.

\begin{tabular}{lcccc}
\hline Variables & $(\mathbf{1})$ & $\mathbf{( 2 )}$ & $\mathbf{( 3 )}$ & $\mathbf{( 4 )}$ \\
\hline Control variables & & & & \\
In $A G D P$ & $0.245^{* * *}(6.98)$ & $0.247^{* * *}(6.99)$ & $0.245^{* * *}(6.95)$ & $0.235^{* * *}(6.70)$ \\
InTR & $0.199^{* * *}(11.06)$ & $0.197^{* * *}(10.42)$ & $-0.201^{* * *}(11.21)$ & $0.212^{* * *}(13.44)$ \\
InIFA & $-0.168^{* * *}(-6.44)$ & $-0.168^{* * *}(-6.45)$ & $-0.168^{* * *}(-6.45)$ & $-0.165^{* * *}(-6.40)$ \\
InFER & $-0.193(-0.32)$ & $-0.199(-0.32)$ & $-0.132(-0.22)$ & $-0.638(-1.01)$ \\
InCPI & $-0.032(-1.32)$ & $-0.031(-1.30)$ & $-0.032(-1.32)$ & $-0.033(-1.41)$ \\
Independent variables & & & & \\
InTAP & $-0.246^{* * *}(-3.46)$ & & & \\
InPM2.5 & & $-0.240^{* * *}(-3.93)$ & & \\
InPM10 & & & $-0.251^{* * *}(-3.41)$ & \\
InSD & $6.596^{* *}(2.79)$ & $6.055^{* *}(2.63)$ & $6.381^{* *}(2.71)$ & $-0.110^{*}(-2.23)$ \\
Constant & 180 & 180 & 180 & $9.058^{*}(2.10)$ \\
Observations & 1.27 & 1.30 & 1.26 & 180 \\
Maximal VIF & yes & yes & yes & yes \\
Year & & & & \\
\hline
\end{tabular}

Notes: ${ }^{*} \mathrm{p}<0.05,{ }^{* *} \mathrm{p}<0.01,{ }^{* * *} \mathrm{p}<0.001 ; t$-values are in parentheses.

\subsection{Robustness checks}

To further demonstrate the reliability of regression results, we use the generalized method of moments (GMM) estimator, that is, the system-GMM estimator, for robustness checks. Comparing with static panel data models (fixed effects or random effects) or ordinary least squares (OLS) regressions, the system-GMM estimator has greater efficiency and less bias [30] which is also commonly used to test the robustness of panel data $[35,36]$

Table 4 shows that the results of regression coefficient between the core explanatory variables, TAP, PM2.5, PM10 and SD, and NIT are significantly negative relationship. The effect of IFA on NIT is also negative and highly significant. Moreover, the coefficients of GDP per capita (AGDP) and tourism revenue (TR) with NIT indicate the positive relationship. These results are consistent with the findings in Table 3.

Table 4. Robustness check results of SYS-GMM.

\begin{tabular}{lcccc}
\hline Variables & $\mathbf{1}$ & $\mathbf{( 2 )}$ & $\mathbf{( 3 )}$ & $\mathbf{( 4 )}$ \\
\hline Control variables & & & & \\
In $A$ GDP & $0.245^{* * *}(7.42)$ & $0.247^{* * *}(7.32)$ & $0.245^{* * *}(7.44)$ & $0.235^{* * *}(7.68)$ \\
InIFA & $-0.168^{* * *}(-6.04)$ & $-0.168^{* * *}(-6.07)$ & $-0.168^{* * *}(-6.04)$ & $-0.165^{* * *}(-6.00)$ \\
InTR & $0.199^{* * *}(10.49)$ & $0.197^{* * *}(10.05)$ & $-0.201^{* * *}(10.28)$ & $0.212^{* * *}(9.49)$ \\
InFER & $-0.193(-0.29)$ & $-0.199(-0.29)$ & $-0.132(-0.19)$ & $-0.638(-0.92)$ \\
InCPI & $-0.032(-1.27)$ & $-0.031(-1.25)$ & $-0.032(-1.26)$ & $-0.033(-1.34)$ \\
Independent variables & & & & \\
InTP & $-0.391^{* * *}(-3.56)$ & & & \\
InPM2.5 & & $-0.332^{* * *}(-3.47)$ & & \\
InPM10 & & & $-0.390^{* * * *}(-3.62)$ & $-0.166^{*}(-2.06)$ \\
InSD & $6.102(1.58)$ & $6.025(1.56)$ & $5.538(1.44)$ & $9.058^{*}(2.14)$ \\
Constant & 180 & 180 & 180 & 180 \\
Observations & 0.697 & 0.697 & 0.697 & 0.705 \\
r2 & yes & yes & yes & yes \\
Year & & & & \\
\hline
\end{tabular}

Notes: ${ }^{*} \mathrm{p}<0.05,{ }^{* *} \mathrm{p}<0.01,{ }^{* * *} \mathrm{p}<0.001 ; t$-values are in parentheses.

In addition, we use sub-sample regression analysis for the sake of comparing the impact of two major air pollutants, PM2.5 and PM10, on inbound tourism in sample 
megacities. Table 5 shows the results of sub-sample regression about the correlation between air pollution and inbound tourism in Chongqing, Beijing and Guangzhou. The results indicate a significant negative correlation between inbound tourists and PM2.5 (coefficient $=-0.327 ; \mathrm{p}<0.001$ ) and PM10 (coefficient $=-0.403 ; \mathrm{p}<0.001$ ) in Chongqing, but the negative correlation is not significant in Beijing. Moreover, it seems that inbound tourists in Guangzhou are not affected by air pollution since the coefficient between inbound tourists and PM2.5 and PM10 become positive correlation without statistically significant.

Table 5. Regression results of sub-sample

\begin{tabular}{|c|c|c|c|c|c|c|}
\hline \multicolumn{2}{|c|}{$\begin{array}{c}\text { (1) } \\
\text { Chongqing } \\
\text { LnNIT }\end{array}$} & \multicolumn{3}{|c|}{$\begin{array}{r}(3) \\
\text { Guangzhou } \\
\operatorname{Ln} N I T\end{array}$} & & \\
\hline \multicolumn{7}{|c|}{ Control variables } \\
\hline In $A G D P$ & \multirow{2}{*}{\multicolumn{2}{|c|}{$\begin{array}{r}-0.180 * *(-2.86) \\
0.277 * * *(9.35)\end{array}$}} & \multicolumn{2}{|l|}{$-0.199 *(-2.63)$} & \multicolumn{2}{|c|}{$-0.126(-1.79)$} \\
\hline $\operatorname{In} T R$ & & & \multicolumn{2}{|l|}{$-0.043(-0.70)$} & \multicolumn{2}{|c|}{$0.292 * * *(4.20)$} \\
\hline $\operatorname{In} I F A$ & \multicolumn{2}{|c|}{$\begin{array}{c}0.277 * * *(9.35) \\
0.018(0.36)\end{array}$} & \multicolumn{2}{|l|}{$0.195(1.33)$} & \multicolumn{2}{|c|}{$0.096(1.96)$} \\
\hline InFER & \multicolumn{2}{|c|}{$-0.942(-1.09)$} & \multirow{2}{*}{\multicolumn{2}{|c|}{$\begin{array}{l}-0.627(-1.23) \\
-0.008(-0.53)\end{array}$}} & \multicolumn{2}{|c|}{$0.735(1.20)$} \\
\hline InCPI & \multicolumn{2}{|c|}{$-0.022(-0.73)$} & & & $0.020(C$ & \\
\hline \multicolumn{7}{|c|}{ Independent variables } \\
\hline In $P M 2.5$ & \multirow[t]{2}{*}{$\begin{array}{l}-0.327 * * * \\
(-3.49)\end{array}$} & & $\begin{array}{l}-0.001 \\
(-0.02)\end{array}$ & & \multicolumn{2}{|l|}{$\begin{array}{l}0.001 \\
(0.73)\end{array}$} \\
\hline In $P M 10$ & & $\begin{array}{c}-0.403 * * * \\
(-3.55)\end{array}$ & & $\begin{array}{l}-0.014 \\
(-0.21)\end{array}$ & & $\begin{array}{l}0.002 \\
(1.39)\end{array}$ \\
\hline Constant & $\begin{array}{l}7.088 \\
(1.51)\end{array}$ & $\begin{array}{r}8.667 \\
(1.80)\end{array}$ & $\begin{array}{l}7.971 \\
(1.76)\end{array}$ & $\begin{array}{l}8.161 \\
(1.79)\end{array}$ & $\begin{array}{l}-2.962 \\
(-0.94)\end{array}$ & $\begin{array}{l}-2.763 \\
(-0.89)\end{array}$ \\
\hline Observations & 60 & & 60 & & 60 & \\
\hline $\mathrm{F}$ & 64.60 & 65.09 & 5.267 & 5.256 & 8.224 & 8.668 \\
\hline $\mathrm{r} 2$ & 0.880 & 0.881 & 0.373 & 0.374 & 0.482 & 0.495 \\
\hline
\end{tabular}

Notes: ${ }^{*}<0.05,{ }^{* *} \mathrm{p}<0.01,{ }^{* * *} \mathrm{p}<0.001 ; t$-values are in parentheses.

The reasons may result from the composition and distribution differences of inbound tourists in sample megacities. In fact, a large number of foreign visitors for the purpose of international business, transnational conference, service staffs and employees (BCSEs), that is, nominal tourists, account for about one third of the total number of inbound tourists in China (see Figure 1).

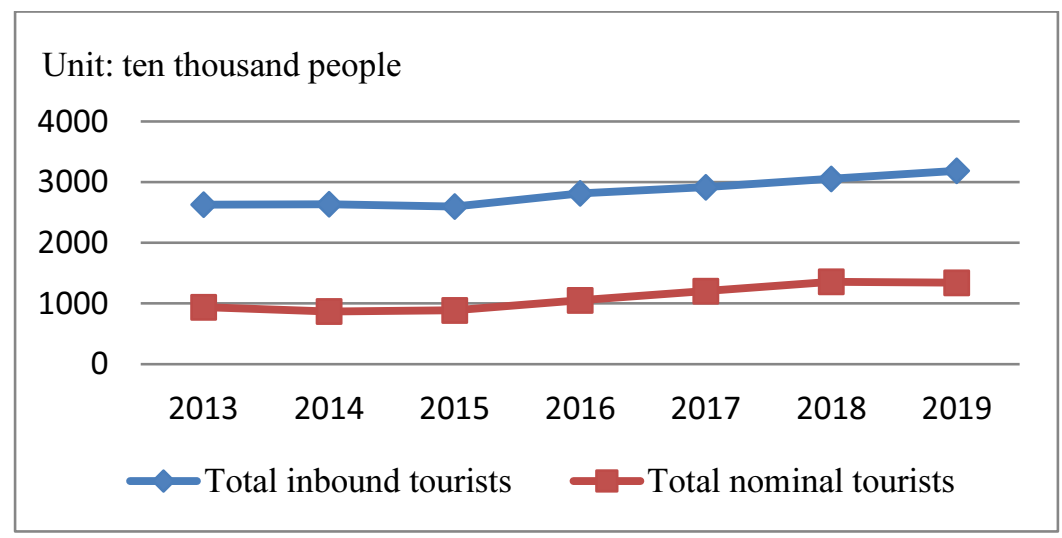

Figure 1. A comparison between the total number of inbound tourists and nominal tourists (2013-2019). Source: National Bureau of Statistics, China. https://data.stats.gov.cn.

Clearly, Beijing is a center of political, economic and cultural, while Guangzhou is the other heavyweight of economic and cultural where holds the fairs of export and import twice a year. Therefore, both of megacities attract a lot of foreign government 
officials, employees and business men whom are not real tourists but have to intensively stay or travel in these cities. Those groups of BCSEs that are recognized as "tourists" by local bureaus of statistics would not be too care about the influence of regular air pollution when they come to Beijing or Guangzhou, even though Guangzhou ranks the second of carbon emissions in global urban [37].

One more puzzle of the results of sum- sample regression is that the regression coefficients on IFA are no statistically significant and have positive correlation with NIT. By contrary, the coefficients on AGDP are significant negative correlation with NIT in Beijing and Chongqing. The possible explanations are as follows:

First, when the control variables IFA are analyzed as independent variables with other variables, the explanatory power of IFA is diluted by other control variables [33].

Second, the main components of GDP (Y) include investment (I), consumption (C) and net exports $(\mathrm{NX})$, that is, $\mathrm{Y}=\mathrm{I}+\mathrm{C}+\mathrm{NX}$ [38]. Among the three component factors, some studies have proved that international trade and consumption don't reduce the size of inbound tourists despite of increasing air pollution [39-41]. IFA is a part of GDP and has dual effects on inbound tourism, expanding the size of inbound tourists by improving tourism infrastructure but decreasing the numbers of foreign tourists due to its carbon emission, for example. Thus, the negative correlation between AGDP and NIT, actually, shows the negative relationship between IFA and NIT.

Third, although the coefficient on AGDP is no significant with NIT in the case of Guangzhou, it should not be recognized that there is no significant negative relationship between IFA and NIT. As previously mentioned, a number of the BCSEs to be classified as tourists (nominal tourists) from different countries, come to Guangzhou for business fairs no matter what air quality is. This special phenomenon does not imply zeroing impact of air pollution on the health of nominal tourists and residents for sure.

The above reasons illustrate that the results of core independent variables and main control variable in Table 5 are no substantial difference from the regression results of benchmark in Table 3 .

\section{Conclusions}

This paper empirically analyzes the effect of air pollution on the number of inbound tourists in major megacities, Beijing, Guangzhou and Chongqing, China. The sample to be selected composes a panel data from January 2015 to December 2019 that allows us to analyze the negative influence of air pollution on the number of inbound tourists before the COVID-19 pandemic.

The empirical results demonstrate that the main air pollutants are linked with PM10 and PM2.5 owing to the combustion of coal, gasoline, fossil fuels and vehicle emissions in sample megacities. Especially, the most serious air pollution is connected with PM10. Furthermore, the effect of air pollution related to carbon emissions from business fixed investment on the number of inbound tourists is a negative correlation, while the influence of GDP per capita and tourism revenue on NIT reveal a positive relationship in accordance with the regression results of benchmark.

The different results between benchmark and sub-sample regressions present that air pollution indeed shrink the size of foreign real tourists but not on nominal ones whom concentrate in Beijing or Guangzhou for business and non-tour purposes. The results of sub-sample confirm the negative relationship between AGDP and NIT, and 
thus provide an evidence about the same correlation between IFA and NIT in Beijing and Chongqing because the control variable IFA is a part of GDP. The exception of Guangzhou case stems from the special situation of nominal tourists. Consequently, there is no reason to deny the empirical results of benchmark by means of some coefficients without significant in sub-sample regression.

In order to stimulate the development of inbound tourism in Chinese megacities, it is essential to reduce carbon emissions associated with business fixed investment in which includes sectors of infrastructure, real-estate and motor vehicles, on fossil fuels based, so that effectively improve air quality from one of important original sources.

The fundamental strategies to lessen air pollution and flourish inbound tourism in megacities are to promote clean energy for green IFA through shifting infrastructure structure from fossil fuel consumption to new infrastructure represented by cloud computing, block-chain and artificial intelligence on information network based, spreading new building materials with green, ecological and environmental protection for real-estate sector, and updating engine, filter and fuel with low carbon emissions for clean diesel vehicles and other vehicles. During the processes of transforming energy type from high carbon fossil to renewable and low carbon, it is essential to popularize clean energy technologies with effective policy frame for radically improving air quality of megacities in China.

\section{Author Contributions}

Nianlin Zhou wrote the manuscript; Yeli $\mathrm{Gu}$ analyzed the data; Manyuan Jiang modified the manuscript. All authors read and approved the final manuscript.

\section{Funding}

This research was funded by the Education Bureau of Guangdong Province of China (Grant No. 2018GXJK272) and the research center of polar issues of South China Business College, Guangdong University of Foreign Studies (Grant No. NGJD 201901) and (Grant No. 20 JD004A).

\section{Acknowledgments}

The authors acknowledge financial support from the Education Bureau of Guangdong Province of China, the research center of polar issues of South China Business College, Guangdong University of Foreign Studies, and editors and reviewers' valuable instructions for revision of this manuscript. The authors are responsible for all errors.

\section{Conflicts of Interest}

The authors declare no conflict of interest. 
Note

(1) The term of megacities means that there are more than 10 million permanent residents living in the same urban areas. Source: The State Council of China, Notice on the adjustment of classification standard of urban scale, The State Council of China [2014] No.51, Oct. 29, 2014.

\section{References}

[1] Danish government. Pioneers in clean energy. 2021. Danish government website. Available online: https://denmark.dk/innovation-and-design/ clean-energy (accessed on 5 March 2021).

[2] Ministry of the Environment. Sweden's climate policy framework. Report of Swedish government. 2021 Mar; 11.

[3] Xi JP. Work together to build a climate governance mechanism of win-win, fair and reasonable. Paris: Speech at the opening ceremony of the Paris conference on climate change. Xinhua News Agency. 2015 Dec; 1.

[4] Wan J, Yan JP, Wang XM, Liu ZQ, Wang H, Wang T. Spatial-temporal pattern and its influencing factors on urban tourism competitiveness in city agglomerations across Guanzhong plain. Sustainability. 2019Nov; (11):1-24.

[5] Lapko A, Panasiuk A, Strulak-Wójcikiewicz R, Landowski M. The state of air pollution as a factor determining the assessment of a city's tourist attractiveness-based on the opinions of polish respondents. Sustainability. 2020 Dec; (12): 1-21.

[6] Yang ZS, Su JH, Yang H. Exploring urban functional areas based on multi-source data: a case study of Beijing. Geography Research. 2021Feb; (2): 477-94.

[7] Deng TT, Liu S, Hu YK. Can tourism help to revive shrinking cities? An examination of Chinese case. Tourism Economics. 2021 May; (5):34-45.

[8] Milewski D. Regionalne uwarunkowania rozwoju turystyki na. Przykładzie. 2019 Jul; (7): 55-68.

[9] Zhou LQ, Bi J. The influence of cultural distance on international tourism destination choices: a case study of Chinese inbound tourism market. Journal of Zhejiang University. 2017 Apr; (4):130-42.

[10] Sun GJ, Qian Q. The impact of air pollution on the development of urban tourism in China . Journal of SCNU. 2020 Sep; (9): 65-73.

[11] Ding L, Wu XG, Ding J. Construction and application of urban tourism competitiveness evaluation index system application. Economic Geography. 2006 Mar; (3): 511-525.

[12] Lapko A, Panasiuk A. Water tourism as a recipient of transport Services on the example szczecin. Transportation Research. 2019 (39): 290-299.

[13] Deng F, Yuan FY, Xu L, Li Z. Tourism, transportation and low-carbon city system coupling coordination degree: A case study in Chongqing municipality, China. International Journal of Environment Research and Public Healthy. 2020 Sep; (17):1-17.

[14] Bieger T, Wittmer A. Air transport and tourism-Perspectives and challenges for destinations, airlines and governments. Journal of Air Transportation Management. 2006 Dec; (12): 40-56.

[15] Becken S, Simmons DG, Frampton C. Energy use associated with different travel choices. Tourism Management. 2003 Dec; (24): 267-277.

[16] Mohamad NS, Deni SM, Ul-Saufie AZ. Application of the first order of Markov chain model in describing the PM10 occurrences in Shah Alam and Jerantut, Malaysia, Pertanika. Journal of Science Technology. 2018 Dec; (26):138-152.

[17] Lin CA, Chen YC, Liu CY, Chen WT, Seinfeld JH, Chou CCK. Satellite-derived correlation of SO22019, NO2, and aerosol optical depth with meteorological conditions over East Asia from 2005 to 2015. Remote Sensing. 2016 Nov; (11): 1738.

[18] Signals EEA. Towards clean and smart mobility. Transport and environment in Europe. European Environment Agency. 2015 Jun; (6): 12-26.

[19] Li L, Liu Y. Study on public negative externality of air quality on inbound tourism in megacities. Ecology Economics. 2019 Oct; (10): 124-139.

[20] Zhang C, Gao AJ, Ding PY. Impacts of haze on the intention to visit china of overseas tourists: based on destination image and risk perception theories. Tourism Tribune. 2017 Dec: (12): 58-67.

[21] Beckens S, Jin X, Zhang C et al. Urban air pollution in China: destination image and risk perceptions. Journal of Sustainable Tourism. 2016 May; (5):1-14. 
[22] Saenz DMO, Rosselló J. Modeling tourism impacts on air pollution: The case study of PM10 in Mallorca. Tourism Management. 2014 Oct; 40(10): 273-281.

[23] Chen SY, Lin BQ. Research status and prospect of economics of energy, environment and climate change in China - a summary of the first forum of Chinese economists on energy, environment and climate change. Economic Research. 2019 Jul; (7): 203-218.

[24] Jiang L, He SX, Cui YZ. Analysis of sulfur dioxide pollution control in China: an empirical study based on satellite observation data and spatial metrology model. Journal of Environment Science. 2021May; (3):1153-1164.

[25] Sun CW, Luo Y, Yao X. The effects of transportation infrastructure on air quality: evidence from empirical analysis in China. Economic Research.2019 Aug; (8):136-151.

[26] Shao S, Li XB, Cao JH. Urbanization promotion and haze pollution governance in China. Economic Research. 2021 Feb; (2):148-164.

[27] Tanpaifang. An effective way to reduce pm2.5.source: controlling carbon emissions in China. 2014. Carbon emissions trading network of China. Available online: http://www.tanpaifang.com (accessed on 11 April 2021)

[28] Liu JY, Chen YP, Xia X. Research on the effect of air pollution on the development of inbound tourism in China. Research Science. 2018 Jul; (7): 1473-1482.

[29] Blancas F, Caballero J, Gonzalez RM, Lozano OM, Perez F. Goal programming synthetic indicators:an application for tourism in Andalusian coastal counties. Ecological Economics. 2010 Feb; (2): 158-172.

[30] Academy of Tourism of China. Annual report on inbound tourism development in China. Beijing: The report of Academy of Tourism of China. 2014. 25-79 pp.

[31] Duan GS. Carbon neutral driving millions investment. Security Daily. 2021 May 22.

[32] Sun GJ, Qian Q. The impact of air pollution on the development of urban tourism in China . Journal of SCNU. 2020 Sep; (9): 65-73.

[33] Lian YJ. Research on investment efficiency of Listed Companies in China. Press of Economic Management. 2009 Aug; (8): 96-102.

[34] Pan SC. Econometrics. Beijing: Press of Renmin University of China; 2009. 112-132 pp.

[35] Faulkender M, Flannery MJ, Hankins KW, Smith JM. Cash flows and leverage adjustments. Journal of Financial Economics. 2012 Jan; 103(1): 632-646.

[36] Warr RS, Elliott WB, Koeter KJ, Oztekin O. Equity mispricing and leverage adjustment costs. Journal of Financial Quantitative Analysis.2012 Sep; 47 (9): 589-616.

[37] Azam M, Khan AQ, Bin AH. The impact of $\mathrm{CO} 2$ emissions on economic growth: evidence from selected higher CO2 emissions economies. Environmental Science and Pollution Research. 2016 Jul; (7): 6376-6389.

[38] Mankiw NG. Essentials of Economics. Boston: Press of Harvard University; 2002. 278 p.

[39] Wang JJ. The Empirical analysis on the relationship between inbound tourism and import \& export trade. Journal of Economic Issues. 2012 Nov; (11): 99-103.

[40] Mi X, Liu ZY. Interactions and regional differences between inbound tourism and international trade in Xinjiang. Journal of L Y Normal University. 2021 Apr; (4):12-18.

[41] $\mathrm{Su}$ JJ, Sun GN, Xu ZY. The pull effect of tourism development on demands for investment, consumption and exports in China. Tourism Tribune. 2014 Feb; (2): 25-35. 